\section{Discussion}

While lymphocytes from patients with malignant disease show moderate lymphocytic sensitization to C.E.A., sensitization also occurs in pregnancy and the early puerperium (where it is higher than in cancer) as well as in multiple sclerosis and other neurological diseases, and especially in G.P.I. Antibody to C.E.A. during pregnancy was reported by Gold (1967). The cellular sensitization to C.E.A. in multiple sclerosis is difficult to explain, but since there is a moderate response in other neurological diseases also it is presumably related to some pathological process which is more developed in multiple sclerosis than in other neurological diseases. That which comes to mind is gliosis. Ever since Charcot (1872) wrote "without doubt [incontestablement] the increase in numbers of neuroglial nuclei and concomitant hyperplasia of the reticulated fibrils is the initial stage, the necessary antecedent [ . . . to demyelination]; the degenerative changes in nervous elements is secondary, consequential," there have been workers who have been struck by the glial proliferative changes in multiple sclerosis which seem out of all proportion to the needs of a simple reparative process (Müller, 1904). Some, indeed, like Charcot have seen glial hypertrophy as an initial stage in the development of multiple sclerosis lesions (Anton and Wohlwill, 1912; Field, 1967; Jacob, 1969). Gliosis is much less pronounced in most other neurological diseases.

An association with extent of parenchymatous destruction and gliosis is further suggested by the results obtained in the small series of patients with G.P.I. it was possible to include. Here too there was pronounced and widespread overgrowth of astroglia. Unfortunately insufficient C.E.A. was available to extend the study and to take in subacute sclerosing panencephalitis, which affords another instance of pronounced glial overgrowth. A difference between G.P.I. and other neurological diseases was also found by Field and Caspary (1972) when lymphocytes were tested against human thymus, the reaction in the former being greater than the latter. Again the cases of G.P.I. stood closer to multiple sclerosis than did other neurological diseases. These relations may depend on gliosis or they may be a consequence of the immunization which follows brain degradation and is more pronounced in G.P.I. and multiple sclerosis than in most other neurological diseases.

Two questions may be posed-( $a$ ) is the response to C.E.A. associated with active tissue proliferation (for example, in pregnancy), or with the increased mitosis in the skin occurring in psoriasis?; $(b)$ is the response to C.E.A. associated with a "semi-malignant transformation" of astroglial cells and thus equivalent to the moderately increased response to Ca.B.P. seen in precancerous conditions? (Field, 1967).
There is some evidence (chiefly biochemical) that multiple sclerosis is a widespread disease of the central nervous system. though the advanced focal changes which result in plaques are so striking that they attract attention almost exclusively. Disturbance of astroglia perhaps through long colonization by a "slow" infective agent might well lead to biochemical changes in seemingly normal white matter at a distance from lesions, while advanced dysfunction would result in histological demyelination. As a supply of C.E.A. becomes more easily available further studies may clarify and extend the observations here presented, especially with regard to the relation between gliosis and lymphocyte sensitization to C.E.A.

We are most grateful to Drs. A. M. Neville and C. W. Turberville, of the Chester Beatty Institute, London, for their generosity in letting us have samples of C.E.A.; to our colleagues of the Newcastle University Hospitals for access to patients under their care; to Dr. J. P. Childs, superintendent of St. Nicholas Hospital, Newcastle, for permission to study patients with G.P.I.; and to Mr. A. Keith and Mrs. J. Cunningham for technical help in the preparation of macrophages and lymphocytes. We are indebted to the North-eastern branch of the Multiple Sclerosis Society, and the Multiple Sclerosis Research Fund Ltd., for supplying the cytopherometers with which this work was carried out.

\section{References}

Anton, G., and Wohlwill, Fr. (1912). Zeitschrift für dir gesamte Neurologie und Psychiatrie, 12, 31.

Bloom, B. R., and Bennett, B. (1966). Science, 153, 80.

Caspary, E. A. (1971). Nature New Biology, 231, 24.

Caspary, E. A. (1972). Clinical and Experimental Immunology, 11, 305. Caspary, E. A., and Field, E. J. (1965). Annals of the New York Academy of Sciences, 122, 182 .

Caspary, E. A., and Field, E. J. (1971). British Medical fournal, 2, 613.

Charcot, J. M. (1872). Leçons sur les Maladies du Système Nerveux, p. 239. Paris, Delacroix.

Coulson, A. S., and Chalmers, E. G. (1967). Immunology, 12, 417

David, J. R., Al-Askari, S., Lawrence, H. S., and Thomas, L. (1964). Journal of Immunology, 93, 264.

Field, E. J. (1967). Deutsche Zeitschrift für Nervenheilkunde, 192, 265.

Field, E. J., and Caspary, E. A. (1970). Lancet, 2, 1337.

Field, E. J. and Caspary, E. A. (1972). Journal of Neurology, Neurosurgery and Psychiatry. In press.
. In

Gold, P., and Freedman, S. O. (1965). Journal of Experimental Medicine, 121, 439.

Hughes, D., and Caspary, E. A. (1970). International Archives of Allergy and Applied Immunology, 37, 506.

Jacob, H. (1969). In Pathogenesis and Etiology of Demyelinating Diseases,

Müller, E. (1904). Die multiple sklerose des Gehirns und Ruckenmarks. Jena,

Fischer.
Smith, J. K., Caspary, E. A., and Field, E. J. (1972). American fournal of Obstetrics and Gynecology, In press..

\title{
Intermittent Secretion of Abnormal Bile in Patients with Cholesterol Gall Stones
}

\author{
R. A. SMALLWOOD, P. JABLONSKI, J. McK. WATTS
}

British Medical fournal, 1972, 4, 263-266

\section{Summary}

Gall bladder and hepatic bile was sampled from 66 patients undergoing elective operations on the biliary

\footnotetext{
Department of Medicine, Austin Hospital, University of Melbourne, Australia

R. A. SMALLWOOD, M.B., M.R.A.c.P., Wellcome Senior Research Fellow in Clinical Science

Department of Surgery, Prince Henry's Hospital, Monash University, Melbourne, Australia

P. JABLONSKI, M.SC., PH.D., N.H. \& M.R.C. Research Fellow

J. McK. WATTS, M.B., F.R.A.C.S., Professor of Surgery
}

tract. Fifty-one patients had cholesterol gall stones but only $59 \%$ of these were found to have bile which was supersaturated with cholesterol. Repeated sampling of hepatic bile from patients with $T$-tubes showed that the secretion of supersaturated bile was intermittent.

These results indicate that it is impossible to separate patients with cholesterol stones from controls simply by examination of the lipid composition of their bile, since an appreciable number of bile samples from patients with cholesterol stones were unsaturated.

The fact that cholesterol gall stones form when the bile is supersaturated with cholesterol only intermittently suggests that the gall bladder may also have a part in their formation. 


\section{Introduction}

The common gall stone in western countries is one which consists predominantly of cholesterol, and in the past few years considerable advances have been made in our understanding of the way these stones are formed. Cholesterol is virtually insoluble in water, and in bile it is held in solution by bile salts and phospholipids in the form of mixed micelles (Spanner and Baumann, 1932; Isaksson, 1954; Hofmann and Small, 1967; Admirand and Small, 1968; Carey and Small, 1970; Small, 1970). Admirand and Small (1968), using an in vitro model system of cholesterol, bile salts, lecithin, and water made up to simulate bile, defined the conditions for cholesterol solubility. They concluded that the relative amounts of these three lipids were the important determinants of cholesterol solubility in bile, and that other factors played little or no part. They showed also that the gall gladder bile of patients with cholesterol stones was saturated or supersaturated with cholesterol, while that from control subjects was unsaturated. This supported the idea that the precipitation of excess cholesterol from supersaturated bile was an important factor in gall stone formation.

Further studies (Small and Rapo, 1970; Vlahcevic, Bell, and Swell, 1970) indicated that the liver was the source of the supersaturated bile; the gall bladder presumably performed a secondary role, providing a receptacle for cholesterol crystals which could coalesce to produce macroscopic stones. The secretion of supersaturated bile appeared to result from a deficiency of bile salts, since cholesterol stone formers were shown to have a diminished bile salt pool (Vlahcevic, Bell, Buliac, Farrar, and Swell, 1970).

The data examined by Small (1970) suggested that the liver rather than the gall bladder was the source of abnormal bile in stone formers. However, other studies (Neiderheiser and Roth, 1968; Dam and Hegardt, 1971) suggested different limits for cholesterol solubility in bile, and failed to show a clear separation between the bile composition of stone formers and controls (Dam and Hegardt, 1971; Danziger, Hofmann, Schoenfield, and Thistle, 1972). The present study was undertaken to provide more extensive data from the Australian population, and to attempt to resolve some of the discrepant findings of previous investigators.

\section{Patients and Methods}

Bile specimens were obtained from 66 patients at elective laparotomy. In 51 patients (stone formers) gall stones consisting predominantly of cholesterol were found. Of the other 15 patients (control group) six had pigment stones and nine had no evidence of gall stone disease. All bile in the gall bladder was aspirated from 40 stone formers and 13 controls. Hepatic bile was aspirated by a catheter inserted through the cystic duct after cholecystectomy in 34 stone formers and six controls. In 23 stone formers and four controls, both gall bladder and hepatic bile samples were obtained. In a further nine stone formers multiple T-tube samples were collected, both before and after the T-tube had been clamped. Specimens containing blood or other detritus were excluded from the study.

Bile samples were frozen after collection and stored at $-15^{\circ} \mathrm{C}$ until processed. Microscopical examination of the thawed samples was carried out under direct and polarized light. Cholesterol (Schoenheimer and Sperry, 1934), bile salt (Iwata and Yamasaki, 1969), and phospholipid (Fiske and Subbarow, 1925) were measured by standard procedures. The mole fractions of bile sale, phospholipid, and cholesterol in each bile sample were calculated.

Gall stones were analysed by dissolving a known amount of the preweighed stone in isopropyl alcohol at $85^{\circ} \mathrm{C}$, filtering the solution, and estimating the cholesterol (Schoenheimer and Sperry, 1934) concentration.

\section{Results}

\section{GALL STONES}

Six patients were found to have pigment stones containing no cholesterol, and these were included in the control group of 15 patients. Forty-six patients had "mixed" stones with a cholesterol content of $75-90 \%$. Five patients had large solitary "cholesterol" stones containing $90-95 \%$ cholesterol.

\section{COMPOSITION OF GALI BLADDER AND HEPATIC BILE}

The mole fractions of bile salts, phospholipid, and cholesterol in each bile sample were expressed as a percentage of the total of all three components, and plotted on triangular co-ordinates. The line A-B in the Figures is the line of maximum solubility of cholesterol determined by Admirand and Small (1968). Points below this line indicate bile with a single phase, unsaturated micellar solution of cholesterol, while points above the line represent bile supersaturated with cholesterol. The latter samples would be expected, after freezing and thawing, to contain cholesterol microcyrstals (Small and Rapo, 1970).

In control patients (Fig. 1) both hepatic and gall bladder bile samples fell within the micellar zone. In three of the four patients in whom gall bladder and hepatic bile samples were obtained simultaneously, there was a difference in the composition of these samples in each patient.

The gall bladder bile (Fig. 2) and hepatic bile (Fig. 3) of stone formers showed wide variations in composition. Only

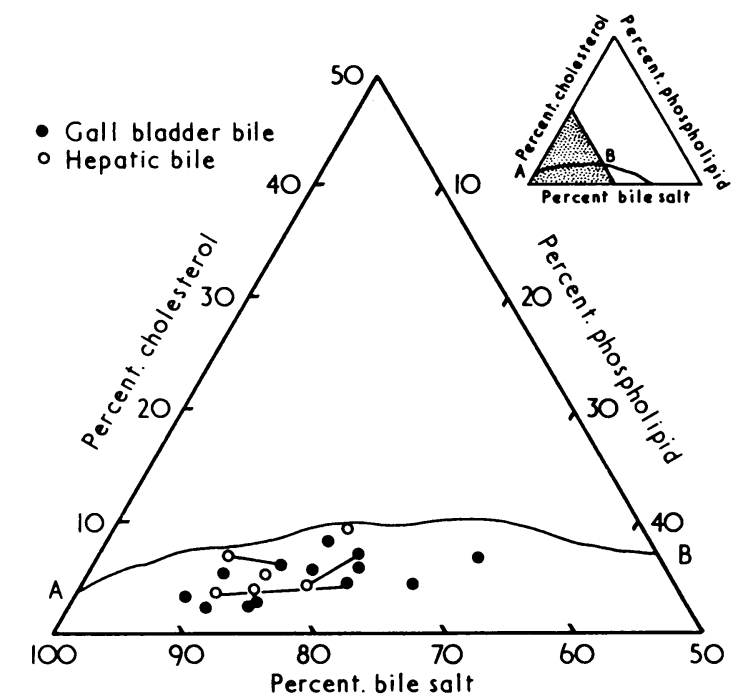

FIG. 1-Composition of hepatic and gall bladder bile from control patients plotted on triangular co-ordinates. Samples of gall bladder bile and hepatic bile obtained simultaneously from individual patients are joined by a line. The inset figure (top right) depicts the part of the phase diagram shown in
The Figs. 1-6.

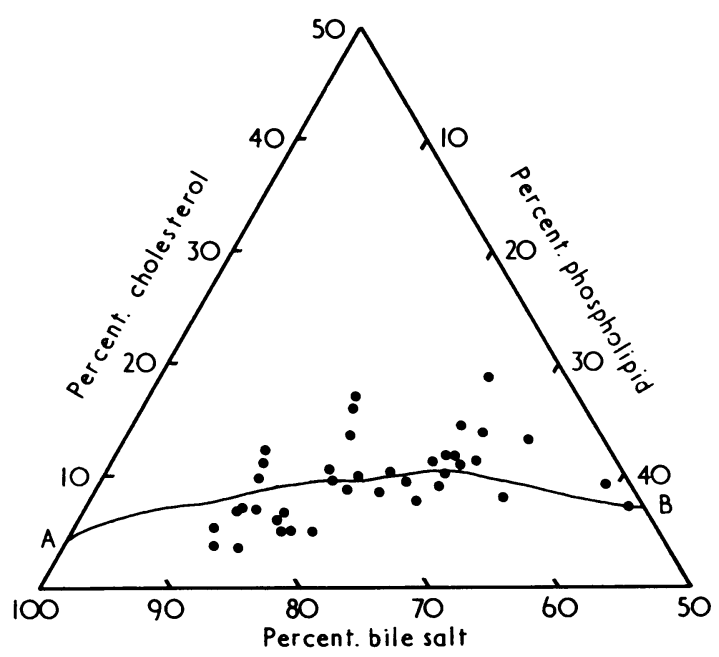
FIG. 2-Composition of gall bladder bile in patients with cholesterol gall
stones. 
$55 \%$ of gall bladder bile samples and $59 \%$ of hepatic bile samples were saturated or supersaturated with cholesterol. The remainder were in the micellar zone. Comparison of Figs. 2 and 3 with Fig. 1 showed an appreciable overlap between bile samples of stone formers and those of controls.

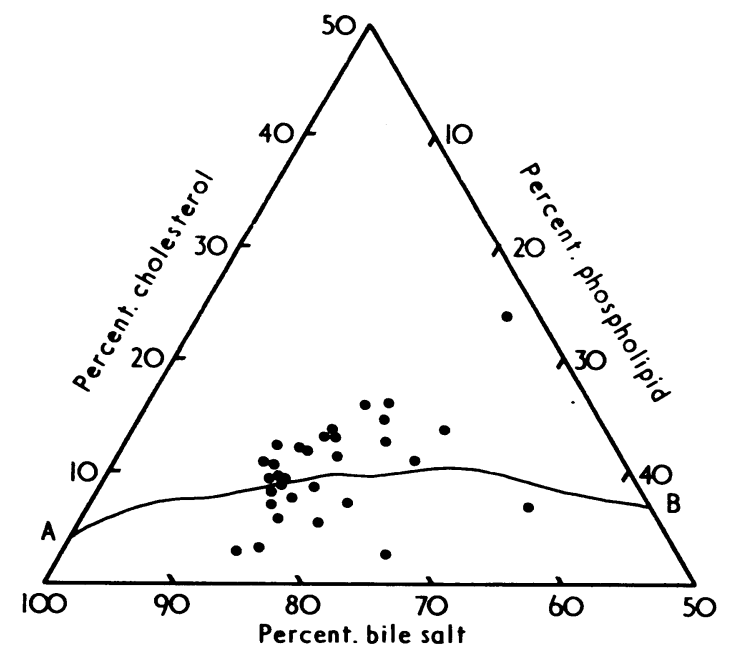

MG. 3-Composition of hepatic bile in patients with cholesterol gall stones.

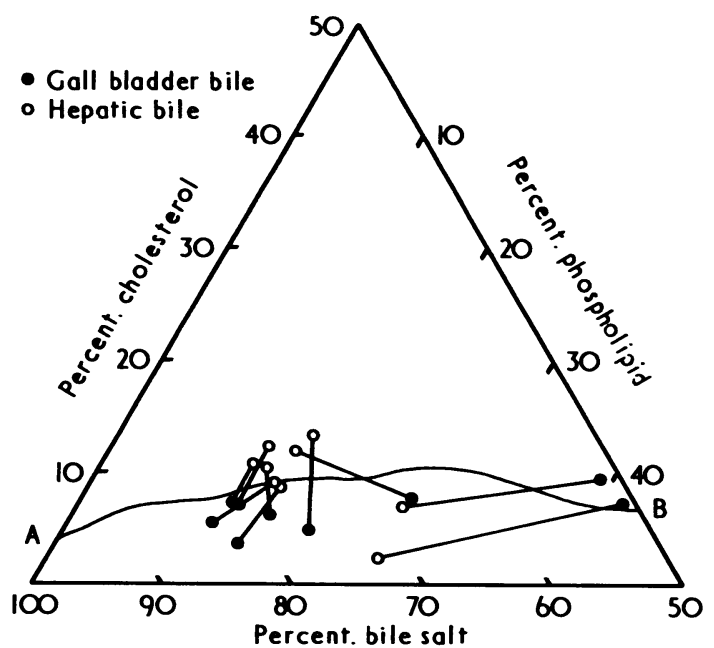

FIG. 4 - Composition of gall bladder and hepatic bile sampled simultancously in nine patients with cholesterol gall stones. Patients with both gall bladder ind hepatic bile samples supersaturated (10) and with both unsaturated (4) are not shown.

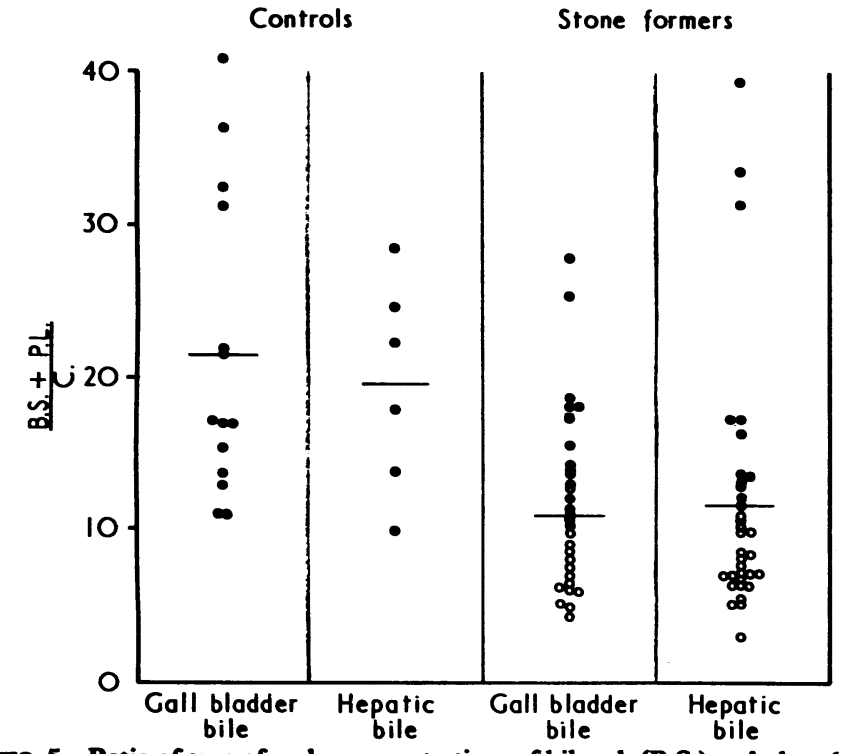

MG. 5-Ratio of sum of molar concentrations of bile salt (B.S.) and phospholipid (P.I.) to cholesterol (C.). O = Supersaturated and saturated bile. $O=$ Unsaturated bile.
Hepatic and gall bladder bile was collected simultaneously from 23 stone formers. Both samples were supersaturated in 10 patients and both were unsaturated in four patients. In two only the gall bladder bile was supersaturated and in seven only the hepatic bile was supersaturated (Fig. 4).

The ratio of the sum of the molar concentrations of bile salt and phospholipid to the molar concentration of cholesterol in each bile sample was calculated (Fig. 5). The mean \pm S.E. of mean ratio for gall bladder bile for the control group (21.3 \pm 2.6) was significantly different from that for the stone formers $(11.0 \pm 0.8, P<0.001)$. Similarly, hepatic bile from controls (19.5 \pm 2.8$)$ had a higher mean ratio than bile from stone formers $(11 \cdot 7 \pm 1.4, \mathrm{P}<0.05)$. There was no difference in the ratios for gall bladder and hepatic bile in the same patient group. All samples with a ratio less than 10 were supersaturated. There were three supersaturated samples, however, with a ratio greater than 10 (Fig. 5).

Cholesterol crystals were identified microscopically under polarized light (Juniper and Burson, 1957). Crystals were detected in all samples of supersaturated bile and in two unsaturated gall bladder bile samples obtained from two stone formers.

Multiple T-tube bile samples were collected from seven stone formers at the time of continuous drainage of bile to the exterior and from two stone formers after the $T$-tube had been clamped for at least $\mathbf{4 8}$ hours.

Most patients (six out of nine) produced both saturated and unsaturated bile samples (Fig. 6). In three patients, however, two with continuous drainage and one with the $T$-tube clamped, all samples were unsaturated. In no patient did bile remain consistently saturated. Samples collected over 12 or 24-hour periods were localized in a more finite area of the phase diagram than samples collected over five-minute periods at random intervals (Fig. 6).

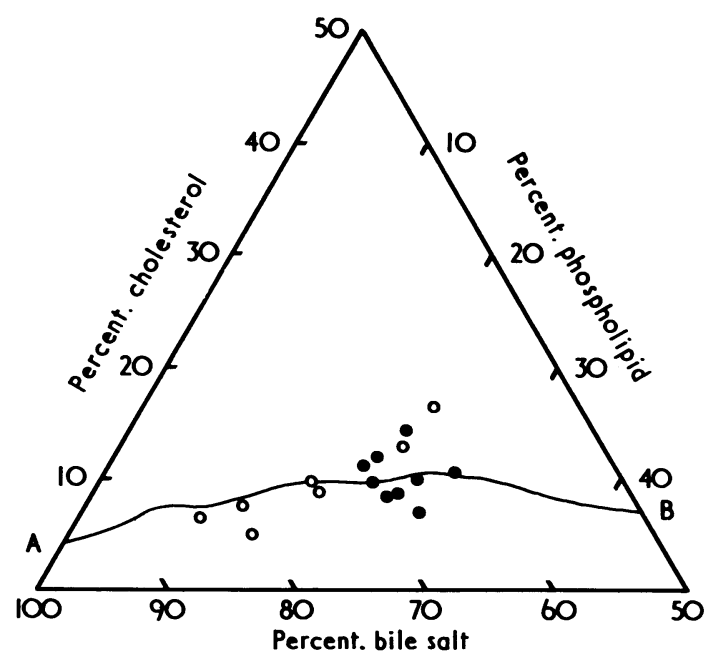

FIG. 6-Composition of hepatic bile samples from the T-tube of two patients after cholecystectomy for cholesterol gall stones. $O=$ Random samples. after cholecystectomy for
$=12$-hour collections.

\section{Discussion}

Admirand and Small (1968) found a complete separation between stone formers and controls when studying the lipid composition of gall bladder bile. In the present study only $55-60 \%$ of bile samples from cholesterol stone formers were supersaturated with cholesterol. Moreover, there was an appreciable overlap between bile samples from stone formers and control patients.

The application of the line demarcating the micellar zone (Fig. 1) calculated from the model system to human bile has been accepted because it successfully separated stone formers from controls in early studies (Admirand and Small, 1968; Small and Rapo, 1970; Vlahcevic, Bell, and Swell, 1970). 
However, the present results and those of others (Dam and Hegardt, 1971; Danziger, et al., 1972) do not show any clear separation. Dam and Hegardt (1971) and Neiderheiser and Roth (1968) defined different boundaries for the micellar region of bile. If we applied their criteria to this study a higher proportion of stone formers would have supersaturated bile, but some control patients would have supersaturated bile. It is, therefore, possible that the limits of cholesterol solubility defined by the in vitro model system (Admirand and Small, 1968) are not applicable to bile, or that some factor other than the relative amounts of bile salt, phospholipid, and cholesterol contributes to the formation of cholesterol gall stones.

Differences have been shown in the solubility of cholesterol in aqueous solutions of various bile salts (Schoenheimer and Sperry, 1934; Neiderheiser and Roth, 1968; Hegardt and Dam, 1971). Cholesterol was more soluble in solutions containing dihydroxy rather than trihydroxy bile salts, but the addition of lecithin increased the solubility of cholesterol and minimized the differences between the effect of the various bile salts (Hegardt and Dam, 1971). It is therefore difficult to interpret the apparently greater ratio of dihydroxy to trihydroxy bile salts in the gall bladder bile of patients with gall stones (Nakayama and Van Der Linden, 1970; Van Der Linden, 1971). Appreciable amounts of lysolecithin in place of lecithin can lower cholseterol solubility (Bouchier, 1971), although the fatty acid-lysolecithin mixture which would result from lecithin breakdown in bile, solubilizes cholesterol just as effectively as lecithin (Neiderheiser and Roth, 1968). Only trace amounts of lysolecithin were detected in the bile of stone formers in the present study.

It is unlikely that differences in individual bile salts and in individual phospholipids account for the high proportion of unsaturated bile samples obtained from stone formers in this study. It appears to be more likely that the secretion of supersaturated bile from the liver is intermittent. Bile samples taken simultaneously from the gall bladder and common bile duct were usually of different composition, and on five occasions in this study bile from one source was supersaturated and the other was in the micellar zone. Similarly, multiple random samples of common bile duct bile from stone formers with $\mathrm{T}$-tubes after cholecystectomy, showed wide variation in composition; samples fluctuated from the supersaturated to the micellar zone. A similar fluctuation into the supersaturated zone also occurred in the T-tube samples of a patient without gall stones after hemihepatectomy for trauma (R. A. Smallwood, P. Jablonski, and J. Mck. Watts, unpublished data). Even normal subjects may at times secrete supersaturated bile (Thistle and Schoenfield, 1971a).

This observation of intermittently supersaturated bile has not been reported by other workers (Thistle and Schoenfield, 1971b; Vlahcevic, Bell, Juttijudata, and Swell, 1971). Their studies, however, were carried out with fasting patients who had strict dietary control. It is possible that both the patient's caloric intake and the characteristics of the diet can affect the composition of bile. Sarles et al. (1969) reported that patients with cholesterol stones had eaten before the onset of their symptoms, a diet higher in calories than matched controls. Sarles et al. (1971) showed that a short-term change in diet can have an effect on the relative molar concentrations of bile salts, phospholipid, and cholesterol. An intake of a high-calorie, high-protein diet for three to seven days increased the incidence of supersaturated bile in four patients with $T$-tubes and an intact enterohepatic circulation of bile salts.

The present observations of intermittent supersaturated bile are consistent with the studies on baboons by McSherry, Glen, and Javitt (1971). They showed a cyclic pattern in the proportions of cholesterol, phospholipid, and bile salt in hepatic bile. During reabsorption of the bile salt pool from the intestines hepatic bile was not supersaturated, but after reabsorption of the bile salt pool hepatic bile was characteristically supersaturated with cholesterol. This cyclical pattern was found to occur irrespective of the presence of cholesterol gall stones.

There is now evidence that patients with cholesterol stones have a smaller bile salt pool than control patients (Vlahcevic et al., 1970; Swell, Bell, and Vlahcevic, 1971). The effect of this smaller pool may be to increase the periods during which bile secreted by the liver is supersaturated. We found, however, that after depletion of the bile salt pool by external drainage through a T-tube some hepatic bile samples still lay within the micellar zone. At no stage did T-tube drainage lead to persistently supersaturated bile. Indeed, in three patients hepatic bile remained unsaturated.

These findings suggest that the continued output of supersaturated bile from the liver may not be the sole prerequisite for cholesterol precipitation. An important primary role for the gall bladder, thought to be unlikely from previous work, cannot be ruled out. In those stone formers who do not appear to produce any supersaturated hepatic bile, the gall bladder may alter the lipid composition of bile. Given the intermittent production of supersaturated hepatic bile the gall bladder may permit cholesterol precipitation by providing a nidus by failing to empty completely, or, perhaps most importantly, by failing to adequately $\mathrm{mix}$ the supersaturated bile with the rest of its contents. Should this bile form a separate stratum in the gall bladder, cholesterol may precipitate even if the rest of the bile in the gall bladder is unsaturated. That stratification of bile can occur in the gall bladder appears to be well established (Thureborn, 1966). The stratification of bile or inability of the gall bladder to empty completely may ultimately prove to be as important in cholesterol gall stone formation as the secretion of supersaturated bile by the liver.

The expert technical help of Mrs. J. Dakin and Mr. M. McClelland is acknowledged. The study was supported in part by a grant from the National Health and Medical Research Council.

Requests for reprints should be addressed to: Dr. J. McK. Watts, Department of Surgery, Prince Henry's Hospital, St. Kilda Road, Melbourne, Victoria, 3004, Australia.

\section{References}

Admirand, W. H., and Small, D. M. (1968). Fournal of Clinical Investigation,

47, 1043.

Carey, M. C., and Small, D. M. (1970). American fournal of Medicine, 49,590 .

Dam, H., and Hegardt, F. G. (1971). Zeitschrift für Ernährungswissenschaft, $10,239$.

Danziger, R. G., Hofmann, A. F., Schoenfield, L. J., and Thistle, J. L.
(1972). New England fournal of Medicine, 286, 1. Fiske, C. H., and Subbarow, Y. (1925). Fournal of Biological Chemistry, 66,375 .

Hegardt, F. G., and Dam, H. (1971). Zeitschrift für Ernährungswissenschaft, $10,223$.

mann, A. F., and Small, D. M. (1967). Annual Review of Medicine,

Isaksson, B. (1954). Acta Societatis Medicorum Upsaliensis, 59, 296.

Iwata, T., and Yamasaki, K. (1969). Fournal of Biochemistry, 56, 424.

Juniper, K., jun., and Burson, E. N., jun. (1957). Gastroenterology, 32, 175. Sherry, C. K., Glenn, F., and Javitt, N. B. (1971). Proceedings of the National Academy of Sciences of the United States of America, 68, 1564. Nakayama, F., and Van Der Linden, W. (1970). Acta Chirurgica Scandinavica, 136, 605.

Neiderheiser, D. H., and Roth, H. P. (1968). Proceedings of the Society for Experimental Biology and Medicine, 128, 221.

Neiderheiser, D. H., and Roth, H. P. (1970). Gastroenterology, 58, 26.

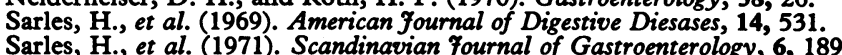

Schoenheimer, R., and Sperry, W. M. (1934). Fournal of Biological Chemistry, 106, 745 .

Small, D. M. (1968). Nerv England Fournal of Medicine, 279, 588.

Small, D. M. (1970). Advances in Internal Medicine, 16, 243.

Small, D. M., and Rapo, S. (1970). New England fournal of Medicine, 283, 53. Spanner, G. O., and Baumann, L. (1932). Fournal of Biological Chemistry,

Swell, L., Bell, C. C., jun., and Vlahcevic, Z. R. (1971). Gastroenterology,

61, 716.
Thistle, J. L., and Schoenfield, L. J. (1971a). New England fournal of Medicine, 284, 177.

Thistle, J. L., and Schoenfield, L. J. (1971b). Gastroenterology, 61, 488.

Thureborn, E. (1966). Gastroenterology, 50, 775 .

Van Der Linden, W. (1971). Gastroenterology, 60, 1144.

Vlahcevic, Z. R., Bell, C. C., jun., and Swell, L. (1970). Gastrocnterology, 59,62 .

Vlahcevic, Z. R., Bell, C. C., jun., Buhac, I., Farrar, J. T., and Swell, L. (1970). Gastroenterology, 59, 165. Vlahcevic, Z. R., Bell, C. C., jun., Juttijudata, P., and Swell, L. (1971).
American fournal of Digestive Diseases, 16, 797. 